\title{
Modeling the transformation from an intensive crop production to a mixed farming system: Integrating banana and ruminant production in the French West Indies
}

\author{
A. Fanchone ${ }^{1 \dagger}$, J.-L. Gourdine ${ }^{1}$, J.-L. Diman ${ }^{2}$ and H. Archimède ${ }^{1}$ \\ ${ }^{1}$ INRA, UR143, Zootechnic Research Unit, F-97170 Petit-Bourg, Guadeloupe, France; ${ }^{2}$ INRA, UR1321 Research unit on tropical agrosystems, F-97170 Petit-Bourg, \\ Guadeloupe, France
}

\begin{abstract}
Introduction
Bananas are one of the main feed resources in tropical humid areas. In these countries, the dominant banana production system is intensive monoculture which induces several environmental problems (pollution, parasite resistance). Although, a fallow has been inserted to break the parasite cycle, it raises the question of the sustainability of such a system. Several studies have shown potential for banana by-products (leaves, pseudo-stem and non marketable fruits) as a green fertilizer following the banana cycleand as a potential feed resource for livestock (Marie-Magdeleine et al., 2009; Mutetikka et al., 2010). However, most of these studies deal with nutritional and digestibility values rather than the integration of banana plantations with farming systems at farm level. The aim of this study was to evaluate the ability to transform an intensive monocultural banana system in mixed farming system including animals, where the fibrous biomass (by-products of the banana production and grass production of the fallow) would allow feeding of ruminants. A modelling approach has been developed in order to evaluate several scenarios comparing monoculture and mixed farming systems for three different ruminant species.
\end{abstract}

\section{Materials and methods}

A static and mechanistic model has been developed. This model was based on experimental data bases, surveys and expertise of stakeholders (farmers and researchers). A farm of ten hectares was simulated, which corresponded to the archetype of banana monoculture farms in the French West Indies. Biomass of banana by products available for feeding animal was estimated from the morphological composition of banana plant, the planting density and the surface of the farm dedicated to banana. Biomass of the fallow available was estimated from INRA data bases on tropical forages. The feeding value of the banana by-products and the animal characteristics (voluntary intake, nutritional requirements, zootechnic performances) have been estimated from different studies carried out at the zootechnic research unit of INRA. Five systems were simulated and compared on the basis of their productivity (banana fruit, livestock and meat): 1) banana monoculture, 2) banana monoculture including fallow, mixed farming systems, with 3) Creole cattle, 4) Martinik sheep, or 5) Creole goats. Due to the available data on performance of sheep fed with banana, only the $5^{\text {th }}$ mixed system with sheep has been validated.

\section{Results and Discussion}

The simulations shown that stocking rate of 1184,285 , and $418 \mathrm{~kg}$ of body weight can be obtained for Creole cattle, Creole goat and Martinik sheep, respectively. Creole cattle would allow a better use of this resource than the other ruminant species studied. However, other parameters such as length of the reproductive cycle, animal selling price, and work time have to be taking into account when choosing the most appropriate ruminant species.

\section{Conclusion}

Due to the area of banana production in the French West Indies, and to the increasing rate of meat importation into these countries the integration of livestock into banana farms would allow increasing self sufficiency in meat from ruminants. . Trials at farm level would allow better evaluation and validiation of the different scenarios studied as well as the provision of information on the transfer of pesticide residues from banana by-products to livestock.

\section{References}

Mutetikka D, Bareeba F and Semakula J 2010. Agricultural Journal 5, 98-100.

Marie-Magdeleine C, Limea L, Etienne T, Lallo CHO, Archimede H and Alexandre G 2009. Tropical Animal Health and Production 41, $1531-1538$.

\footnotetext{
${ }^{\dagger}$ E-mail: Audrey.Fanchone@antilles.inra.fr
} 